\section{COMMUNITIES OF PEER PRACTITIONERS}

Experiences from an Academic Writing Group

by Roger Andre Søraa, Lina Ingeborgrud, Ivana Suboticki, Gisle Solbu

Learning academic writing is important for communicating research and participating in scholarly debates. This learning is traditionally conceptualized through a hierarchical teacher-student relation or individual accomplishment. However, in this paper we ask how we might understand the development of academic writing skills as a collective practice within a writing community. We draw on experiences from our own departmental writing group of PhD candidates and highlight our specific peer community as a tool and the draft texts we deliver as boundary objects through which we develop and broaden
\end{abstract} our academic skills. 


\section{N}

NORDIC JOURNAL

of Science and Technology Studies

\section{Introduction}

Academic writing is one of the most important means of communicating research and participating in the academic community. For PhD candidates, the development of writing skills is imperative for engaging in the publishing realm of academia and its ongoing debates. In Norway, PhD candidates in the social sciences and humanities - who often have little or no prior publishing experience - must write either a monograph or a minimum of three publishable articles during their doctoral work. Our own university recognizes the need for fostering writing skills in PhD candidates by, for instance, providing writing courses and faculty-organized writing groups with supervision. While these resources may help $\mathrm{PhD}$ candidates to become better writers (and we have ourselves experienced some direct benefits from such courses and groups), learning to write is predominantly focused on language, structure, and other aspects of communicating results, and it does not necessarily see academic writing as an integral part of the research process itself. Moreover, learning to write is conceptualized in terms of knowledge transfer from the skilled to the unskilled. In this paper, however, we explore our own journey of developing writing skills in a self-organized writing group for PhD candidates.

We started our writing group because we wanted to be more closely engaged with the PhD candidates in our own department - the Department of Interdisciplinary Studies of Culture - with whom we hoped to improve our writing abilities. Inspired by The Agraphia Model, introduced in a rather straightforward "academic self-help book" (Silvia 2007(r)), we started our group in 2015. In preparing this paper, our initial aim was to share some practical tips with other early career researchers who might be interested in developing similar groups; but as we delved into an analysis of our experiences in the writing group, we realized that they might be of interest to a broader audience. Most notably, we found the role of communities in the learning process to be of particular interest. As $\mathrm{PhD}$ candidates within the field of Science and Technology Studies (STS), we also noted that perspectives on sociomaterial approaches to community learning were missing in the literature.

Several authors have written about the importance and benefits of writing groups (for an overview, see Aitchison and Guerin $\left.2014^{[r]}\right)$. Apart from pointing to the quantifiable advantages of writing groups in the number of papers produced (Page-Adams et al. $\left.1995^{[r]}\right)$, scholars have also stressed more qualitative benefits related to the development of members' writing skills. For instance, Aitchison (2009 $9^{[r]}$ ) illustrates how academic learning is facilitated by the practices of writing, reading, and commenting on texts, discussing texts with peers, and redrafting texts. In effect, she argues that writing is learned not only through writing, but also through critiquing text - a point also stressed by Caffarella and Barnett
(2000 $\left.0^{[i]}\right)$. Hence, giving feedback on other scholars' work is beneficial for developing one's own writing skills. Furthermore, scholars have also suggested that writing groups may help to demystify the process of writing (Ferguson 2009 $9^{[r]}$ ), enabling writers to better understand the process (MacLeod, Steckley, and Murray 2012[i]) and thus to fear it less and engage in it more actively (Badley $2006^{[[]}$).

Moreover, scholars have noted that writing groups are beneficial for reasons that extend beyond the immediate craft of writing. Aitchison and Guerin (2014 $4^{[r]}$ :12) stress that writing groups provide an important emotional safe space for doctoral students and early career researchers. Those who are still in the process of developing a researcher identity may find the companionship of a group to impart a sense of connectedness and belonging to an academic community. Aitchison (2003 $\left.{ }^{[[]}\right)$specifically emphasizes the collegiality amongst group members as an important source of support for PhD students as they form an academic identity. Similarly, Hadjioannou and colleagues (2007[r]) note that the human relationships in writing groups are particularly important in PhD students' lives, which they claim are usually dominated by insecurity and isolation. They describe how the human relationships within such groups empower their members. Likewise, psychological benefits, including a positive attitude, confidence, and motivation, were highlighted in a study of a writing group at Sheffield University (Ferguson 2009 $9^{[r]}$ ), while another study attended to the emotional benefit of such groups, in the form of increased pleasure in writing (Dwyer et al. 2012 ${ }^{[r]}$ ). We find these insights helpful and recognize them in our own experiences. However, we also see some limitations in these studies.

The literature on writing groups is limited by a predominant focus on supervisor-led groups and a secondary focus on texts, themselves, as the main output of the groups. BBy contrast, we ask: What is the role of writing groups, in early career researchers' academic development? How might such groups, or communities, be created and sustained? Through a critical exploration of our own group, and experiences, we argue that writing groups and the materialization of writing in these groups can be understood as tools for developing skills as academic practitioners.

The article is structured as follows: First, we introduce a theoretical framework in which we draw on a sociomaterial knowing-in-practice approach to learning and employ the notion of Community of Practice (COP). Second, we provide the methodological background of the analysis of our writing group. Third, we empirically describe the organization of our group and our experiences related to this, following the three pillars of CoPs. Finally, we conclude and elaborate on the findings. 


\section{Knowing in Communities of Practice}

Within the practice turn in the social sciences (Schatzki, Knorr Cetina, and von Sevigny $\left.2007^{[\mathrm{r}}\right)$, learning is considered a situated activity - something that people do together while they are engaged in everyday practices. In this regard, the term "knowing-in-practice" promotes the idea that learning is a practical accomplishment situated in a particular historical, social, and cultural context. This is also referred to through the idioms of "situated learning" and "practice-based theorizing" (Lave and Wenger 1997[r]; Gherardi 2000[]; Orlikowski 2002[i]; Gherardi and Perrotta 2014 ${ }^{[\mathrm{r})}$. In contrast to cognitive learning theories, knowing-in-practice, and situated learning perspectives share an understanding of knowledge and learning as social and cultural phenomena. In other words, "knowing" describes "what people do every day to get their work done" (Orlikowski 2002 [r]: 249). Learning and doing are thus closely connected. In our analysis, we build on this approach, in particular by exploring how it relates to participation in our Agraphia writing group. Thus, we draw attention to situated learning as a community activity.

Several scholars have engaged with learning in communities, and Lave and Wenger (1997[r) were the first to propose the idea that learning involves engagement in Community of Practice (COP). Rather than understanding learning as the acquisition of certain forms of knowledge, Lave and Wenger situate learning in social relationships. Their basic argument is that CoPs are everywhere, consisting of groups of people who share a concern or passion for something they do and who improve their skills as a result of regular interaction. A COP can be defined as a relatively stable community with face-to-face interaction between members who work closely together, wherein participation is central to learning and knowledge generation (Lave and Wenger $1999^{[(r)}$ ). According to Wenger $\left(1998^{(r)}\right)$, three elements distinguish a CoP from other groups and communities:

1) Domain: The identity of a CoP is defined

by a shared domain of interest.

2) Community: in pursuing their interest in that

domain, members engage in joint activities and dis-

cussions, help each other, and share information.

3) Practice: members of a COP are practitioners, and

they develop a shared repertoire of experiences, stories,

and tools. This takes time and sustained interaction.

These elements distinguish the CoP from, for instance, networks or other forms of group organization, by emphasizing collective characteristics and dynamics, rather than personal gains (Wenger $\left.1998^{[i]}\right)$. In this paper we explore how these key characteristics have developed and changed over time in our particular community. A more detailed analysis of these three aspects highlights the way in which community learning is facilitated in an academic context.

In this paper we also explore learning between peers as a specific type of learning community, as suggested by Haas (2014 $\left.4^{[r]}\right)$. According to Lave and Wenger (1997[]: 37), participants in a CoP progress from so-called "legitimate peripheral participation" to "full participation" as they gain competency and increase their involvement in the main community processes. For newcomers, the purpose is to learn to talk as the community in order to become a full member (Lave and Wenger 1997[1]: 108-9). By contrast, in this paper we explore how participation and learning can be understood within a community that lacks predefined hierarchies and has more symmetrical relations between members.

The sociocultural perspectives on learning presented so far do not include material aspects in the learning process. Orlikowski (2006 $\mathrm{G}^{[\mathrm{r}}$ ), in particular, makes an important contribution to the sociotechnical approach to learning by criticizing previous research for giving too little attention to material and technological aspects of learning practices. In this way, she offers a more symmetrical view of the types of actors involved in CoPs. For instance, Johnson's (2004 $4^{[r]}$ ) study of the integration of simulators as artifacts in new medical learning practices compellingly illustrates a sociomaterial context for learning. Drawing this back to traditional CoP literature, Wenger (1998 $8^{[i]}$ ) explains that CoPs should not be understood as pedagogical methods that can be implemented, and claims that the design of a CoP is unimportant. Practice is thereby not a result of design, but a response to it, as it is subject to negotiation (Wenger 1998 $8^{[n]}: 233$ ). In this regard, Wenger (1998 [r]: 235) argues that "design" is a boundary object, rather than a learning method, and describes a boundary object as functioning "as a communication artifact around which communities of practice can negotiate their contribution, their position, and their alignment." Here, we draw on these insights and explore sociomaterial approaches to learning, highlighting the boundary objects that are important in our case.

In sum, we use situated learning perspectives in CoPs to examine learning in a sociomaterial setting. We ask: How might we understand collective learning in CoPs within non-hierarchical peer communities? What learning tools are important and what role do they play in such communities? Before we delve into these questions, we will briefly comment on our method of analytically exploring our own experiences in our writing group.

\section{Researching and Reflecting on Ourselves}

This paper is based on our own experiences with a peer writing group at our department. We were inspired by a book on writing by Silvia $\left(2007^{[r]}\right)$, titled How to Write a Lot. In this text, Silvia recommends the formation of a so-called "agraphia group." He claims 


\section{N}

NORDIC JOURNAL

of Science and Technology Studies

that writing groups support people who want to write better and faster, on the basis that motivation, goal setting, and social support are crucial for the maintenance of good writing habits (Silvia 2007[r]: 50). As founding members of our Agraphia group, we have seen it grow and develop over the past two years, and this has given us the opportunity to reflect on its processes. We started our group in February 2015 and have since held approximately forty meetings. Since a good deal of time has gone into preparing for these meetings, the group has played a rather considerable role in our PhD journeys. While originally we had no intention of writing a paper about the group, in fall 2016 we determined that our experiences might be relevant for a broader audience.

Initially, each of us created a detailed account of our thoughts about the group structure, the main benefits of the group, and what worked well or was challenging. After reading each other's reflections, we concluded that the group had certain qualities that extended beyond the immediate craft of writing. This made us particularly interested in how we could conceptualize learning within our group. While the reflections in the empirical section of this article are mainly based on our own experiences, we also asked other group members to share their thoughts on specific

\section{Assembling Our Own Community}

Writing groups can take many forms, but as Aitchison and Guerin $\left(2014^{[r]}\right.$ : 6) stress, they are perhaps not for everyone. Without support and know-how, many people experience frustration in their attempts to establish and maintain groups. In our case, we were initially unsure of what the group dynamics would be and what we would actually gain by taking part in the community. In this section, we delineate some of our reflections about learning as a COP.

\section{Developing a shared domain of interest}

We started with the same basic aim as most other writing groups - to write more and to write better. We all wanted to practice writing within a safe environment of peers, and this was important for our development of a shared domain of interest. To us, a safe space was a place with no predefined hierarchies, where members would have relatively more authority to engage in discussions than in other academic settings, such as the larger academic department, groups with unfamiliar members from other institutes, and supervisory groups. In a safe space, we would be able to experience and participate in a "tough" but non-judgmental commenting environment. Also, some group members found it challenging to gain familiarity with all of the new faces in the department, and the Agraphia community helped to smooth this transition. The fact that members already interacted on a daily basis made it easier for us to formalize our ties in a group. Becker (1986[r] ) stresses that trust is key in academic writing, and that trust is developed by overcoming the struggles and challenges of writing, together. While this was already stressed in Silvia's advice, it gained a different meaning issues, such as leaving the group, their motivation for continuing, and aspects of interdisciplinarity. After several new PhD candidates joined the department in spring 2017, the Agraphia writing group split into two smaller groups. The experiences and reflections in this article stem from members of the original group.

Although our initial reflections about the group were quite similar, our process of writing about the group was fairly complex. We wrote the first drafts of this article using Google Docs - a platform on which all four authors could comment on and see their co-authors' edits and suggestions in real time. This was an interesting and enjoyable way to write, but it was also challenging, and manifested a few points that we wanted to make in this paper. Namely, it illustrated that writing is one aspect of a broader and collaborative research process. In our case, it was subject to several discussions in which we had to negotiate, argue, and compromise our points of view and personal writing styles. As researchers within a constructivist tradition, we were aware that this process of writing about and analyzing the group also created and enacted the group, to some degree. In the following section, we explore our writing community in detail, focusing on its establishment, organization, and maintenance.

for us over time. A Peer can be understood in different ways (e.g. relating to age, experience, research topic, etc.). In our case, the title of "PhD Candidate" represented, on the one hand, a formalized set of shared expectations and status; but on the other hand, we attached different meanings to the qualities that we felt should establish us as peers within this community. Namely, creating and engaging in a community of equals was as much a domain of interest that formed the peer group as it was an outcome of our shared identity.

Aitchison $\left(2003^{([)}\right)$explains that activities surrounding writing, such as commenting on texts written by peers, contribute to improving writing skills. In our group, members have gradually become more involved in other members' writing projects, and this has made it easier for us to discuss members' articles and projects. Our interest in discussing writing was rather narrow at the start, but we soon realized that by interacting with each other's texts we would develop more than simply writing skills. In this way, our shared domain of interest moved from a focus on writing, itself, to collective development as academic practitioners through writing.

\section{Organizing the community}

Shared interests not only create a group and hold it together, but they are also constructed once members start interacting around a common interest. The Development of a shared domain of interest in our group was closely intertwined with routines and explicitly stated rules, though these rules were - and still are - subject to negotiation. According to Lave and Wenger (1999 $\left.]^{[r]}\right)$, there is no 


\section{N}

NORDIC JOURNAL

of Science and Technology Studies

clear design for interaction in CoPs. In our case, however, clear rules strengthened engagement, predictability, and commitment from the very beginning.

Currently, the group meets every other Friday (from 11:00 am to 12:00 pm) to discuss members' texts and writing progress. Initially, several members expressed frustration when other members failed to submit or read a text, or even forgot the meeting. Regular group hours were thus introduced to avoid misunderstandings and frustration due to differing expectations. We also established a clear instruction: members must be present to read and deliver a text at the agreed time. The meetings themselves were also given a clear structure, which continues to this day. Each meeting begins with coffee and food, in order to relax members and maintain group commitment. Knowles and Grant (2014 $\left.{ }^{[i]}\right)$ point out that food plays a pivotal role in creating a focused, energetic atmosphere in writing sessions and that it can create social bonds through gift exchange (Guerin 2014). Eating and drinking thus draws individuals into a group that looks after its members (Aitchison 2014 ${ }^{[r]}$ : 13). Our department solidifies its support of our group by granting "fuel" for our writing.

Following refreshments, the meeting is divided into two main parts. Since sharing academic texts and giving and receiving feedback are the most important objectives of the group, we use approximately 45 minutes of each meeting to discuss a text written by one of the members. For each meeting, two members are selected to do a close reading of the text and to provide constructive criticism on that piece. When submitting a text, the author is asked to define the specific issues on which he or she wants feedback (e.g. the language, argument, use of concepts, structure, etc.). However, the main readers are free to comment on any issue they find relevant. Other group members are encouraged to also read the text, though they are not expected to comment with the same level of detail as the main readers (but often the texts are so exciting that all members read them thoroughly, anyway). When a member receives comments that lead to an interesting discussion about his or her work, that member feels inclined to give the same experience to other members. In this way, reciprocal relationships are constructed, and these relationships form and sustain the community. The remaining fifteen minutes of each meeting are spent monitoring writing progress. Each member reports whether he or she has fulfilled their two-week personal goal and sets a new goal for the next meeting. Although the group supports ambition, we have lately become more aware of the need to set clearly defined and realistic goals. The last few minutes of each meeting are spent planning the subsequent meeting. This includes choosing an author and two main readers. We have our own "Agraphia book" - what Silvia $\left(2007^{[r]}\right)$ calls the "Folder of Goals" - which we use to reinforce good writing behavior through a system of butterfly and star stickers: at each meeting, the author gets a butterfly and the two main readers each get a star attached to their names. The stickers work as nice visual rewards, and they also make it easier for us to keep track of group members' activity levels.
Wenger (1998 $8^{[n]}: 235$ ) claims that the design of a practice community is a boundary object, rather than a learning method. By contrast, we argue that in our group, the design (our community rules) serves as an important tool for facilitating learning. From the start, we established clear rules, which have been renegotiated along the way. This has given us predictability, ensured that expectations are fulfilled, and made sure that each member has the time and space to contribute to the group discussion. While the rules were particularly important in the beginning, when the group was forming, over time, they have become routinized practices. Reproduction of these practices is no longer linked to social control, but is generated by the recognition of the benefits we gain from organizing our meetings in this way.

\section{Learning as practitioners}

The Agraphia group has become a tool through which we collectively develop academic skills as practitioners. Through meeting regularly, discussing texts, and sharing experiences, we demystify the practice of writing. We have discovered that learning in this setting is multifaceted. Here, we highlight our learning and development of writing skills and - more importantly - our growth as academic practitioners.

We have recognized that being too critical and perfectionist in regard to our own writing may create a deadlock or slow down the writing progress. Thus, we push each other to deliver drafts we consider far from "ready." During our meetings, we comment on the structure of findings and paragraphs, engagement with the reader, and the author's voice in the narrative. More detailed and language-related comments are not given much space; rather, such comments are written directly in the text for the author to review at a later point. If a text is near completion, more time is devoted to concrete textual issues. Usually, however, other topics are prioritized. These practices have revealed something that is perhaps self-evident to many: learning to write is about much more than mere writing. For instance, in the first meetings, we realized that commenting on the structure of a text could not be removed from discussions of the content of the argument, itself. By default, we engaged in a debate about structure, the analytical standpoint of the author, and compelling angles from which to approach the academic debate in question. Opening the "black box" of writing and sharing writing difficulties has thus proved to be closely connected to the difficulties of doing research and analysis, and not least, positioning these within wider academic debates. By engaging with each other's texts and writing, we have learned to be more proficient academics.

Both the texts, themselves, and the meta-language we develop when discussing them, are key to learning in the writing group. According to Aitchison (2003 $3^{[r]}$ ), researchers develop a meta-language and a meta-conscious awareness when they talk about writing processes. In our case, the texts serve as important objects of our developing meta-language. By gathering around the texts, so to speak, we strengthen our academic skills in broader terms. 
Thus, the texts can be described as important boundary objects for learning. In a community of peers in which everyone works in different research groups or on specific PhD projects, the texts we share allow us to learn as a community. As mentioned, this learning relates not only to writing, but also a number of other aspects. First, when discussing particular texts, members often suggest new concepts, methods, frameworks, and studies that could help to expand our overall knowledge of the field. Second, this contributes to more affinity for various positions within theories of science. Third, our discussion of writing in progress pushes us to find key points and novelties in our material, often at an early stage, in both our own and other members' material. We have had good experiences with requesting the main author is asked to provide a verbal summary of the material, which forces him or her to explicate the main point to an audience. All in all, the use of texts as central objects of engagement invites our broader engagement in writing as a means of developing as academic practitioners.

Developing meta-languages is also essential for strengthening and managing our interdisciplinarity. All of the group members are employed in the Department of Interdisciplinary Studies of Culture, which is connected to different scholarly traditions, such as anthropology, literature, computer science, and the arts. Also, the group members work on a variety of topics (e.g. energy, gender, transport, robots). Thus, we have had to develop our communication and translation skills in order to come together as a group. This has required us to not only see other members' perspectives but also to be eloquent in formulating our own ideas and our arguments for these ideas. Listening to others formulate their thoughts and experiencing their misunderstanding of a perspective helps members improve and adjust their ways of communicating. We have often experienced misunderstandings and difficulties when readers and authors have approached a text through divergent disciplinary approaches. For example, we have had several discussions about how authors should present and analyze quotes in a text. On one occasion, an author found his quote well described and positioned, but another saw it as assumed and underexplored. In this case, the author had to critically examine his position and argue why his presentation of quotes was legitimate. While such discussions comprise one of the group's main strengths, we also acknowledge that the interdisciplinarity requires "management," as also recognized by Sørensen and colleagues (2008 $\left.{ }^{[r]}\right)$. For this reason, we usually try to assign main readers whose research foci are closely aligned to the topic of the paper.

One of the main characteristics of our group is that it is comprised of peers, and we learn with and from each other. When several new PhD candidates joined the department in spring 2017, we consciously chose to divide the group in two, in order to avoid new members entering a group that had already developed shared practices and a common domain of interest. We, the members from the original writing group, provided some informal guidelines and advice to the new PhD candidates on organizing a writing community, but they were free to develop their own shared domain and community rules.

According to Lave and Wenger (1999 ${ }^{[r]}: 37$ ), members in a CoP move from so-called "legitimate peripheral participation" to "full participation" as they gain competency and increase their involvement in the main community processes. In our case, learning occurred as all members became "fuller" participants, developing their skills together with the other members, as a community. By creating an intentionally low threshold for delivering texts from the start and developing relationships of trust, we experienced that comments from peers could feel less dangerous than critical feedback from more senior academics. This perceived safety enabled us to be more outspoken with our opinions, to put more effort into our translation of meanings, and to give more space for co-constructing knowledge. To give an example of the opposite, a very experienced scholar once visited our group to give some pointers. In this meeting, a different type of exchange quickly became evident, due to the senior academic's greater experience and higher academic position. By contrast, we feel that engaging in a peer community gives us more leeway to negotiate meanings.

\section{Conclusion: Learning in Communities of Peer Practitioners}

In this article we have shared and reflected on our own practices of creating and sustaining a writing group in our department. We have drawn on a knowing-in-practice approach to learning and employed the concept of CoP to highlight the importance of knowing and learning as collective practices among group members. Moreover, we have adopted a sociomaterial approach to learning in order to draw attention to both human and non-human actors in the learning process. Thus, the article has both an empirical and a theoretical aim: (1) to share experiences from our writing group and reflect on its strengths in relation to other forms of learning, and (2) to use these findings to develop ways of thinking about collective learning through CoPs.
According to Wenger (1998[r]: 226), learning involves the ability to renegotiate new meanings and to engage in boundary work. In our community, renegotiation was enabled by the non-hierarchical peer community. Further, we have stressed how the texts shared in every meeting become important boundary objects and tools for developing academic skills, such as honing an analytical sensibility, giving and responding to feedback, and creating meta-language in order to communicate within and between fields. In other words, writing might not always be the goal, in itself; rather, it might be a means of improving other academic skills. The text serves as an object that is discussed, negotiated, argued, agreed, and struggled over by the 
community. Also, the design of the Agraphia group is an important tool for maintaining its practices. Ultimately, the group assembles many actors at every meeting - academic texts, sandwiches, PhD candidates, the Agraphia book, and (star and animal) stickers. Thus, the group helps members improve as academic practitioners and further prepares them to engage in dialogue with other academics.

As expected, the Agraphia group helps members learn not by observing the community, but by actively participating in the community. This finding is in line with Lave and Wenger (1997[r), who stress that the main goal of community members is to learn how to become full members - to learn how to talk as the community. This resonates with the literature of knowing-in-practice, as it considers learning to be a practical accomplishment. However, this knowing-in-practice is not only an individual development, but also a collective achievement. Thus, the writing group is the entity that learns, grows, and develops.

\section{Acknowledgments}

The authors would like to thank everyone who has contributed to our Agraphia group, two helpful readers Professor Thomas Berker

\section{References}

Aitchison, C. 2003. Thesis writing circles. Hong Kong Journal of Applied Linguistics 8: 97-115.

Aitchison, C. 2009. Writing groups for doctoral education. Studies in Higher Education 34: 905-16.

Aitchison, C. and Guerin, C. 2014. Writing groups for doctoral education and beyond: Innovations in practice and theory. New York, NY: Routledge.

Badley, G. 2006. Using writing groups to transform university teachers into scholarwriters. Unpublished manuscript.

Becker, H. S. 1986. How to start and finish your thesis, book, or article. Chicago, IL: University of Chicago Press.

Caffarella, R. S. and Barnett, B. G. 2000. Teaching doctoral students to become scholarly writers: The importance of giving and receiving critiques. Studies in Higher Education 25: 39-52.

Dwyer, A., Lewis, B., McDonald, F., and Burns, M. 2012. It's always a pleasure: Exploring productivity and pleasure in a writing group for early career academics. Studies in Continuing Education 34: $129-44$.

Ferguson, T. 2009. The 'write' skills and more: A thesis writing group for doctoral students. Journal of Geography in Higher Education 33: 285-97.

Gherardi, S. 2000. Practice-based theorizing on learning and knowing in organizations: An introduction. Organization 7 (2): $211-23$.

Gherardi, S. and Perrotta, M. 2014. Becoming a practitioner: Professional learning as a social practice. In International
A novel contribution from our work is the importance of building a symmetrical community of peers with no pre-defined academic hierarchy. In our community, there is no dominant knowledge transfer from senior to junior community members, and no legitimate peripheral participation. Rather, members are expected to actively engage from the very start, and encouraged to give feedback on texts immediately upon joining the group. This skill requires regular practice, and unfortunately, such practice is often neglected in formal doctoral training. To highlight the peer element, we propose an addition to the concept of the CoP, namely what we call the "Community of Peer-Practitioners" (COPP). This community should not be taken as a substitution for a COP, but should be understood as reflecting a slightly different - egalitarian - way of practicing a learning community, as befitting the situation and needs of early career researchers. We have highlighted the benefits of engaging in a COPP and we invite others who are interested in writing communities to further explore peer groups.

and Dr Kristine Ask in our department, and the two anonymous reviewers for their insightful comments on this article.

handbook of research in professional practice-based learning, edited by S. Billett, C. Harteis, and H. Gruber, 139-62. Dordrech: Springer International.

Guerin, C. 2014. The gift of writing groups: Critique, community and confidence. In Writing groups for doctoral education and beyond: Innovations in practice and theory, edited by $\mathrm{C}$. Aitchison and C. Guerin, 128-43. New York, NY: Routledge.

Hadjioannou, X., Shelton, N. R., Fu, D., and Dhanarattigannon, J. 2007. The road to a doctoral degree: Co-travelers through a perilous passage. College Student Journal 41: 160.

Haas, S. 2014. Pick-n-Mix: A typology of writers' groups in use. In Writing groups for doctoral education and beyond: Innovations in practice and theory, edited by C. Aitchison and C. Guerin, 30-49. New York, NY: Routledge.

Johnson, E. 2004. Situating simulators: The integration of simulations in medical practice. Lund: Arkiv förlag.

Knowles, S. and Grant, B. 2014. Walking the labyrinth: The holding embrace of academic writing retreats. In Writing groups for doctoral education and beyond: Innovations in practice and theory, edited by C. Aitchison and C. Guerin, 110-27. New York, NY: Routledge.

Lave, J. and Wenger, E. 1991. Situated learning: Legitimate peripheral participation. Cambridge: Cambridge University Press.

MacLeod, I., Steckley, L., and Murray, R. 2012. Time is not enough: Promoting strategic engagement with writing for publication. Studies in Higher Education 37 (6): 641-54. 
Orlikowski, W. J. 2002. Knowing in practice: Enacting a collective capability in distributed organizing. Organization Science 13 (3): 249-73.

Page-Adams, D., Cheng, L.-C., Gogineni, A., and Shen, C.-Y. 1995. Establishing a group to encourage writing for publication among doctoral students. Journal of Social Work Education 31: 402-7.

Schatzki, T. R., Knorr Cetina, K., and von Savigny, E. 2001. The practice turn in contemporary theory. London: Routledge.
Silvia, P. J. 2007. How to write a lot: A practical guide to productive academic writing. Washington, DC: American Psychological Association

Sørensen, K. H., Gansmo, H. J., Lagesen, V. A., and Amdahl, E. 2008. Vitenskap som dialog - kunnskap i bevegelse. Tverrfaglighet og kunnskapskulturer i forskning. Trondheim: Tapir akademiske forlag.

Wenger, E. 1998. Communities of practice: Learning, meaning and identity. Cambridge: Cambridge University Press. 